\title{
Determination of the positive weather year for application in hygrothermal simulations
}

\author{
J. Kočí, J. Maděra \& R. Černý \\ Department of Materials Engineering and Chemistry, Faculty of Civil \\ Engineering, Czech Technical University in Prague, Czech Republic
}

\begin{abstract}
Quite a few methods for the determination of characteristic weather years is available in the scientific literature. However, the positive weather year as opposed to the critical weather year is practically unheeded, although the alternation of positive and critical weather years in the service life prediction analyses may significantly increase the reliability of those simulations. In this paper, a simplified approach for the selection of the positive weather year for hygrothermal analyses in the Czech Republic is presented. This approach is designed for the locations with incomplete weather data sets. The lack of weather data is handled by replacing the missing data by Test Reference Years (TRY) from different locations with similar climate. After that, each weather year is ranked by the damage function and an inverse relationship between the damage function value and the respective weather year is found. Finally, several historical weather years in the Czech Republic are selected as the candidates for the positive year and the method is verified by a comparison with TRY.

Keywords: hygrothermal simulations, positive weather year, climatic data, inverse modelling, partial weather data.
\end{abstract}

\section{Introduction}

Sophisticated building simulations are an integral part of the current practice of the designing process. The growing complexity of involved materials and their multi-layered systems has logically reflected in the demands on the design process. The key part of design remains the stress and strain analysis. However, other aspects of design, such as the hygrothermal and energy performance have a high priority as well. 
The most important part in hygrothermal analysis of any building construction is the input weather data. In the numerical simulations it is very common to use Test Reference Years (TRY) [1-3] or Typical Meteorological Years (TMY) [4-6] as input data. Unfortunately, there are some drawbacks within the use of this data as the construction of TRY or TMY consists in averaging of real weather data from several decades from the past. Therefore, the most severe and most favorable years are hidden behind this average. The TRY or TMY are suitable for long-term simulations of energy or hygrothermal performance. In case of investigation of moisture induced damage, it is necessary to use weather data that includes sudden or rapid changes. In the literature, such weather year is known as a critical weather year [7-12]. The critical weather year is used to simulate most severe conditions in the studied locality with respect to a particular kind of damage. In the hygrothermal simulations the critical year may be used for example for service life analysis. However, there exist some situations when a strict use of critical weather year is not appropriate. The critical weather years should be used for short-term analysis only, as it is highly unlikely that more than 2 or 3 critical years will occur consecutively in the nature. Using such a weather year for long-term simulation brings an excessive level of safety to the calculations which may devalue the reliability of the results. For the serious long-term hygrothermal analysis or service life assessment it is necessary to combine critical weather years together with normal or positive years. In the case of frost resistance of building materials, the critical weather year is supposed to be cold and humid, so that such conditions that enable water in the pore system to freeze are induced to the construction. Contrary to the critical year, the positive year may contribute to the accumulation of moisture in the construction during the season and when followed by the critical year, more severe hygrothermal stress may be induced to the construction. For that reason it is convenient to investigate both critical and positive weather years and use them together. Moreover, the global warming that is frequently discussed over the last years may have significant influence on the long-term simulations (30 or more years) as the TRY will probably change during that period. Therefore, it may be more suitable to at least combine the positive weather years with TRY to obtain more reliable results.

In this paper a novel approach for determination of a positive weather year is proposed. The approach is designed for locations where the long-term weather data is not available. An extensive description how to handle the problem with missing weather data has been proposed in [12]. First, the artificial long-term weather data history is created for a given location using reference years from localities with similar climate. Then, each reference year is ranked by the damage function based on the hygrothermal response of studied constructions and the inverse analysis is carried out in order to derive mathematical formulas linking the weather data to the damage function value. The damage is defined in terms of frost resistance, however, it could be replaced by any damage function typical for studied location. Finally, the particular weather year is selected based on the presented approach and the verification of the method is done by comparison with TRY for studied location. 


\section{Positive weather year selection}

The process of selection of the positive weather year requires several consecutive procedures to be carried out. These procedures include collection of historical weather data, computer simulation for chosen types of building envelopes, hygrothermal analysis of simulation results and ranking each weather year by the damage function. Finally, the inverse analysis is applied and the relation between the damage function value and the respective weather year is determined for each studied construction.

\subsection{Collection of historical weather data}

The availability of weather data is crucial for application of weather data selection methods. Such data are well available in the USA or in some European countries. Unfortunately, there are still many locations and countries worldwide where the weather data history is missing. The history of weather data must contain hourly values of temperature, relative humidity, wind direction and velocity, rainfall and solar radiation for at least past 20 years. In the case there is a lack of historical weather data, it must be filled with an artificial data [12]. As the proposed method is designed to be used in the Czech Republic, the missing weather data were substituted by TRYs from different locations with similar climate. The list of chosen localities is shown in Table 1. All data were obtained using Meteonorm software, version 6.1 [13], which is meteorological database and computer program for climatological calculations for locations all over the world.

Table 1: List of used test reference years.

\begin{tabular}{ll}
\hline Name & Country \\
\hline 1 Atlantic City, NJ & USA \\
2 Bodo & Norway \\
3 Columbia, MO & USA \\
4 Dublin & Ireland \\
5 Lerwick & Scotland \\
6 London & England \\
7 Nantes & France \\
8 Reykjavik & Iceland \\
9 Hradec Kralové & Czech Republic \\
10 Mannheim & Germany \\
11 Uccle & Germany \\
12 Warzsava & Poland \\
13 Graz & Austria \\
14 Nancy & France \\
15 Kopenhavn & Denmark \\
16 Štrbské Pleso & Slovakia \\
17 Churáňov & Czech Republic \\
18 Bourges & France \\
19 Grossenzersdorf & Austria \\
20 Osnabrueck & Germany \\
21 Budapest & Hungary \\
\hline
\end{tabular}


The climate in the Czech Republic is characterized by both hot summers and cold winters and therefore some of the substituting weather years are chosen from regions with hot summer (e.g., Nantes, Atlantic City) and some of them from region with very cold winters (Štrbské Pleso, Churáňov, Grossenzersdorf).

\subsection{Definition of the studied wall systems and computer simulation of their hygrothermal performance}

The determination of the positive weather year was done on the several types of building enclosure that are typical for the Czech Republic. These types were represented by load-bearing materials from cement based materials such as concrete and autoclaved aerated concrete (AAC). These materials were provided with thermal insulation on different basis - expanded polystyrene, hydrophilic or hydrophobic mineral wool. The final plasters were chosen with respect to the material composition. The list of studied building envelopes is shown in Table 2.

Table 2: List of studied wall systems.

\begin{tabular}{|c|c|c|c|}
\hline & $\begin{array}{c}\text { Load-bearing } \\
\text { material }\end{array}$ & Thermal Insulation & Plaster \\
\hline 1 & Concrete & N/A & Baumit MVR Uni \\
\hline 2 & Concrete & $\begin{array}{l}\text { Mineral wool, } \\
\text { hydrophobic }\end{array}$ & Baumit MVR Uni \\
\hline 3 & Concrete & $\begin{array}{l}\text { Mineral wool, } \\
\text { hydrophilic }\end{array}$ & Baumit MVR Uni \\
\hline 4 & Concrete & Expanded polystyrene & Baumit MVR Uni \\
\hline 5 & $\mathrm{AAC}$ & $\mathrm{N} / \mathrm{A}$ & Baumit MVR Uni \\
\hline 6 & $\mathrm{AAC}$ & $\begin{array}{l}\text { Mineral wool, } \\
\text { hydrophobic }\end{array}$ & Baumit MVR Uni \\
\hline 7 & $\mathrm{AAC}$ & $\begin{array}{l}\text { Mineral wool, } \\
\text { hydrophilic }\end{array}$ & Baumit MVR Uni \\
\hline 8 & $\mathrm{AAC}$ & Expanded polystyrene & Baumit MVR Uni \\
\hline
\end{tabular}

For each building envelope listed in Table 2, computer year-long simulations were carried out, using climatic data of the localities listed in Table 1 . In the simulation of the hygrothermal performance, the simulation tool HEMOT [14] was used, which is based on the general finite element package SIFEL [15]. The material parameters used in the computational simulations were obtained from several sources [16-20].

\subsection{Definition of the damage function}

The choice of damage function must be done with respect to the particular location. As the weather in the Czech Republic is characterized by an alternation of the freezing and thawing periods, typical damage for that locality is represented 
by presence of freeze/thaw cycles in the surface layers of the building envelopes. Therefore, the Winter Index damage function is used in this paper [12]. This function calculates the severity of each weather year in terms of induced frost in the construction. The damage function calculates the integral over the surface layer of the construction only when the conditions for water freezing are met $\left(T<T_{0}\right.$ and $R H>R H_{0}$ ). The limits are usually set as $\mathrm{T}_{0}=0^{\circ} \mathrm{C}$ and $\mathrm{RH}_{0}=95 \%$. The damage function is defined as:

$$
W I=\sum\left(T-T_{0}\right)\left(R H-R H_{0}\right)
$$

The ranking process according to Eq. (1) assigns the damage function value to each building envelope under different weather years. As it obvious from Eq. 1 the values of WI are negative due to the negative temperature subtraction. The lower value the damage functions returns, the more severe conditions in the construction occurred. If the WI is equal to zero, the construction is void of any freezing stresses.

\subsection{Inverse analysis of damage function values}

As it has been mentioned in the introduction, contrary to the USA, where the weather years are fully covered by meteorological data, in our case we needed to find some simplification, taking into account the Czech Republic's weather data coverage conditions. Therefore, it was necessary to find optimum between the available weather data, its price and last but not least, the quality of optimization results. As the damage function in this research is calculated in terms of frost resistance, it was decided to use monthly weather data of temperature, relative humidity and precipitation as the only input values.

To find the relationship between weather data and damage function values, an inverse analysis was employed. Such inverse analysis led to an optimization problem and to solve this issue, the genetic algorithm GRADE was used [21-23]. The mathematical description was optimized in following form:

$$
Y_{\text {pred }}=c_{0}+c_{1}\left(T_{w} R H_{w}\right)+c_{2}\left(T_{w} R R_{w}\right)+c_{3}\left(T_{s} R H_{s}\right)+c_{4}\left(T_{s} R R_{s}\right),
$$

where $c_{0}-c_{4}$ are the optimized variables, $T_{w}$ is the average temperature in the winter period (November-March), $T_{s}$ the average temperature in the summer period (April-October), $R H_{w}$ the average relative humidity in the winter period, $R H_{s}$ the average relative humidity in the summer period, $R R_{w}$ the average monthly precipitation in the winter period, $R_{\mathrm{s}}$ the average monthly precipitation in the summer period.

The aim of the optimization was to find such combination of $c_{0}-c_{4}$ coefficients that produced the minimal difference between WI and $\mathrm{Y}_{\text {pred }}$ for a given construction. For each building envelope's material composition 16 weather years were used to optimize the mathematical function (2) as input data for the genetic algorithm and remaining 5 weather years were used for the prediction within this optimization. In this way we were able to verify the optimization process. The results of the optimizations are shown in Fig. 1, the optimized coefficients from Eq. (2) are shown in Table 3. 


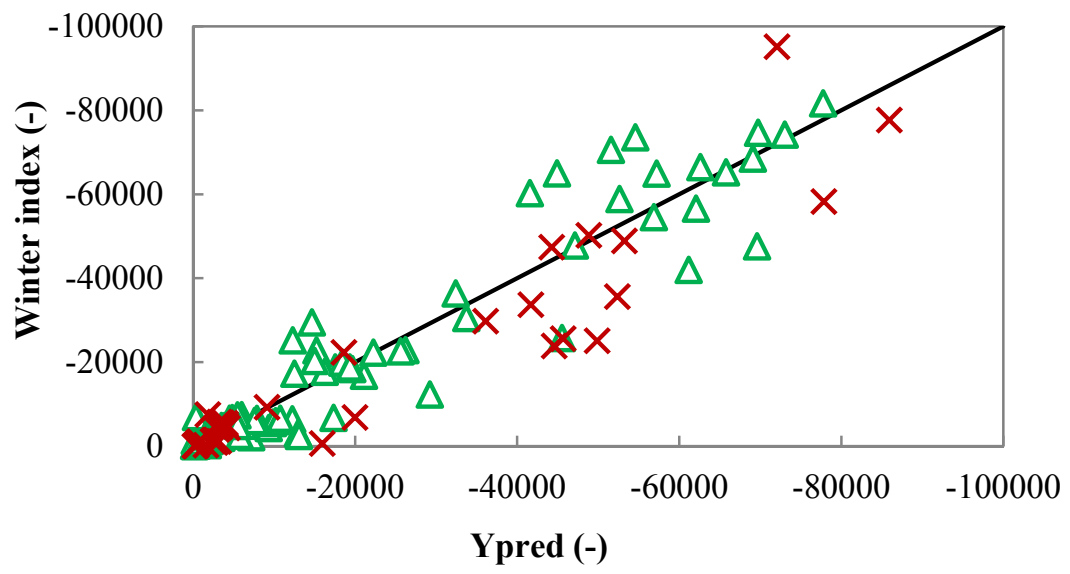

$\triangle$ Optimization $\times$ Prediction

Figure 1: Optimization results of studied wall systems.

Table 3: Optimized coefficients.

\begin{tabular}{|c|c|c|c|c|c|}
\hline \multirow{2}{*}{$\begin{array}{c}\text { Wall } \\
\text { system }\end{array}$} & \multicolumn{5}{|c|}{ Optimized coefficients (-) } \\
\hline & $\mathrm{c}_{0}$ & $\mathrm{c}_{1}$ & $\mathrm{c}_{2}$ & $c_{3}$ & $\mathrm{c}_{4}$ \\
\hline 1 & -1267.1 & -0.215 & 0.626 & 1.355 & -0.548 \\
\hline 2 & -6449.7 & 8.747 & -9.659 & 1.296 & 2.476 \\
\hline 3 & -28695.0 & 142.430 & -12.878 & -68.820 & 42.099 \\
\hline 4 & 2285.8 & 28.546 & 1.517 & -31.777 & 9.739 \\
\hline 5 & -8374.3 & 6.618 & -9.617 & 3.782 & 1.699 \\
\hline 6 & -6352.2 & 9.388 & -14.786 & 1.324 & 2.236 \\
\hline 7 & -39187.0 & 122.960 & 16.928 & -56.784 & 35.198 \\
\hline 8 & -60841.0 & 127.700 & 22.896 & -39.971 & 35.642 \\
\hline
\end{tabular}

\section{Verification of the positive weather year}

The results of the inverse analysis were applied on the monthly averages of temperature, relative humidity and precipitation for the locality of Prague, Czech Republic. Using the monthly averages instead of hourly values of weather data brought significant savings as the 30 -year weather data history in form of monthly averages is very cheap in comparison with the same set of weather data hour by hour. Results of the application of the found inverse relations are shown in Table 4. 
Table 4: Application of inverse relations to the monthly averages of 30-year weather data history of Prague, Czech Republic.

\begin{tabular}{|c|c|c|c|c|c|c|c|c|}
\hline \multirow{2}{*}{ Year } & \multicolumn{8}{|c|}{ Wall system \# } \\
\hline & 1 & 2 & 3 & 4 & 5 & 6 & 7 & 8 \\
\hline 1982 & -190 & -23757 & -3754 & -72530 & -3644 & -79262 & -3768 & -74773 \\
\hline 1983 & -610 & -14198 & -2996 & -42971 & -3635 & -57142 & -3098 & -49962 \\
\hline 1984 & -368 & -19970 & -3490 & -61171 & -3679 & -70918 & -3548 & -65281 \\
\hline 1985 & -498 & -21298 & -4318 & -74360 & -4426 & -86295 & -4228 & -78306 \\
\hline 1986 & -418 & -20625 & -3195 & -61726 & -3342 & -71408 & -3254 & -66262 \\
\hline 1987 & -535 & -21138 & -3900 & -71349 & -4025 & -83415 & -3812 & -75984 \\
\hline 1988 & -495 & -15132 & -3110 & -43987 & -3666 & -55821 & -3335 & -49703 \\
\hline 1989 & -653 & -9165 & -2757 & -25839 & -3769 & -42202 & -2929 & -34216 \\
\hline 1990 & -440 & -11715 & -2912 & -31167 & -3711 & -43907 & -3153 & -37558 \\
\hline 1991 & -460 & -17389 & -4034 & -58805 & -4423 & -71264 & -4061 & -63404 \\
\hline 1992 & -489 & -13352 & -3336 & -40747 & -4022 & -54104 & -3484 & -46813 \\
\hline 1993 & -614 & -14107 & -3681 & -48012 & -4328 & -62963 & -3752 & -54356 \\
\hline 1994 & -620 & -7265 & -2626 & -17593 & -3771 & -33632 & -2917 & -26016 \\
\hline 1995 & -744 & -10548 & -3811 & -39842 & -4734 & -57777 & -3889 & -47433 \\
\hline 1996 & -473 & -22308 & -4490 & -77663 & -4521 & -88403 & -4482 & -80813 \\
\hline 1997 & -374 & -17435 & -3028 & -49336 & -3402 & -59382 & -3181 & -54275 \\
\hline 1998 & -304 & -19556 & -2745 & -53118 & -2956 & -61581 & -2856 & -57700 \\
\hline 1999 & -611 & -11771 & -3231 & -37054 & -4048 & -52393 & -3360 & -44241 \\
\hline 2000 & -413 & -14416 & -3302 & -41307 & -3899 & -52247 & -3610 & -46306 \\
\hline 2001 & -459 & -17971 & -2824 & -50741 & -3169 & -61219 & -2971 & -56221 \\
\hline 2002 & -309 & -18585 & -2557 & -45235 & -2834 & -51026 & -3090 & -48953 \\
\hline 2003 & -551 & -14497 & -4016 & -51390 & -4628 & -66333 & -4011 & -57194 \\
\hline 2004 & -287 & -20149 & -3084 & -56769 & -3249 & -64680 & -3241 & -60605 \\
\hline 2005 & -413 & -18956 & -3277 & -57000 & -3545 & -67382 & -3354 & -61738 \\
\hline 2006 & -549 & -15316 & -3156 & -46855 & -3707 & -60159 & -3238 & -53180 \\
\hline 2007 & -330 & -14618 & -1706 & -28954 & -2279 & -37792 & -2035 & -35276 \\
\hline 2008 & -314 & -15680 & -1691 & -32651 & -2185 & -41471 & -1929 & -38962 \\
\hline 2009 & -800 & -8003 & -3347 & -28693 & -4462 & -47416 & -3518 & -37367 \\
\hline 2010 & -623 & -16462 & -3567 & -54947 & -4044 & -69118 & -3587 & -61097 \\
\hline 2011 & -289 & -19425 & -2278 & -49004 & -2497 & -56985 & -2402 & -54041 \\
\hline
\end{tabular}


Analyzing the predicted values of WI presented in Table 4, the weather years 2007 and 2008 were selected as the positive years for most studied wall systems. These weather years were compared analogically with the monthly averages of TRY for Prague. Results of the verification is shown Table 5. If the predicted value of WI selected weather years is higher than TRY then the weather year is more favorable to the construction.

Table 5: Comparison of selected positive years with TRY for Prague, Czech Republic.

\begin{tabular}{|c|c|c|c|c|}
\hline & Wall system & 2007 & 2008 & TRY \\
\hline 1 & Concrete & -329 & -314 & -408 \\
\hline 2 & Concrete + MW, hydrophobic & -14617 & -15680 & -16752 \\
\hline 3 & Concrete + MW, hydrophilic & -1705 & -1690 & -2597 \\
\hline 4 & Concrete + Expanded polystyrene & -28954 & -32650 & -44277 \\
\hline 5 & AAC & -2279 & -2185 & -3025 \\
\hline 6 & AAC + MW, hydrophobic & -37791 & -41471 & -54411 \\
\hline 7 & AAC + MW, hydrophilic & -2035 & -1929 & -2788 \\
\hline 8 & AAC + Expanded polystyrene & -35276 & -38961 & -49909 \\
\hline
\end{tabular}

\section{Discussion}

The presented research is based on the assumption of having incomplete weather data. Therefore, some simplifications are involved in the procedure for the determination of the positive weather year. The simplifications consist in replacing missing weather years with TRY from other location with similar climate and in using monthly averages of temperature, relative humidity and precipitation only [12]. Therefore, some uncertainty is brought to the selection process. On the other hand, such simplification is definitely cost saving, as the temperature, relative humidity and precipitation belong to the group of data that is measured quite easily.

The application of this approach should thus be done with respect to the simplifications mentioned above. Solar radiation that is neglected in the calculations may significantly warm up the surface of the construction and contribute to the water evaporation and overall reduction of the moister content. The same situation appears when considering wind speed and wind direction. The wind also enables the liquid water in the surface layer of the construction to evaporate. Neglecting these factors is reflected in lower (i.e. worse) values of predicted WI, which is on the safe side of the calculations. However, wind factors together with precipitation, known as "driving rain" may worsen the hygric conditions in the construction, so that the values of WI will be lower in a real situation. Therefore, using of this approach should be limited to such locations, where the neglected weather factors are not in excessive levels. 
To complete the verification process it is necessary to obtain hourly values of weather data from the years 2007 and 2008. Thanks to this method, it is not necessary to complete and order the whole 30-year weather data set, which can lead to the cost savings as high as $93 \%$. However, the comparison of the simulation with hourly data for each wall system must be done.

\section{Conclusions}

This paper described the process of selection of the positive weather year for hygrothermal simulations, which is suitable for locations with incomplete weather data. The missing weather data were replaced by TRY from different locations with similar climate and in this way, the artificial weather data history was created. After that, year-long simulations of hygrothermal performance of studied wall systems were carried out and each wall system in combination with different weather years was ranked. Finally, an inverse analysis was applied with some necessary simplifications and mathematical formulas linking the damage function values and respective weather years were found. The simplification in the inverse analysis process consisted in using monthly averages of temperature, relative humidity and precipitation only which brought significant savings of the cost while keeping the accuracy of this approach on a sufficient level. The application of the derived relations pointed at two different historical years from the Czech Republic weather history as the candidates for the positive weather year, namely 2007 and 2008. The suitability of these years was verified by comparing them with the TRY for the same location. The results of the verification confirmed the applicability of the proposed method.

\section{Acknowledgement}

This research has been supported by the Czech Science Foundation, under project No P105/12/G059.

\section{References}

[1] Bilbao, J., Miguel, A., Franco, J.A. \& Ayuso, A., Test reference year generation and evaluation methods in the continental Mediterranean area. Journal of Applied Meteorology, 43(2), pp. 390-400, 2004.

[2] Kalamees, T. \& Kurnitski, J., Estonian test reference year for energy calculations. Proceedings of the Estonian Academy of Sciences, 12(1), pp. 40-58, 2006.

[3] Lee, K., Yoo, H. \& Levermore, G.J., Generation of typical weather data using the ISO Test Reference Year (TRY) method for major cities of South Korea. Building \& Environment, 45(4), pp. 956-963, 2010.

[4] Chan, A.L.S., Chow, T.T., Fong, S.K.F. \& Lin, J.Z., Generation of a typical meteorological year for Hong Kong. Energy Conversion and Management, 47(1), pp. 87-96, 2006. 
[5] Oko, C.O.C. \& Ogoloma, O.B. Generation of a typical meteorological year for Port Harcourt zone. Journal of Engineering Science and Technology, 6(2), pp. 20-214, 2011.

[6] Zang, H., Xu, Q., Du, P. \& Ichiyanagi, K. A modified method to generate typical meteorological years from the long-term weather database. International Journal of Photoenergy; Article ID 538279, p. 9, 2012.

[7] Rode, C. Reference years for moisture calculations. Report T2-DK-93/02, IEA Annex 24 Hamtie, Denmark, 1993.

[8] Geving, S. Moisture design of building constructions: hygro-thermal analysis using simulation models - part I and II ( $\mathrm{PhD}$ thesis). Norwegian University of Science and Technology, Faculty of Civil and Environmental Engineering, pp. 41-55, 1997.

[9] Hagentoft, C.E. \& Harderup E., Climatic influences on the building envelope using the $\pi$-factor. IEA Annex 24 Hamtie, Task 2: environmental conditions. Closing seminar, Finland, 1996.

[10] Cornick, S., Djebbar, R. \& Dalgliesh, W.A., Selecting moisture reference years using moisture index approach. Building \& Environment, 38(12), pp. 1367-1379, 2003.

[11] Salonvaara, M., Sedlbauer, K., Holm, A. \& Pazera, M. Effect of selected weather year for hygrothermal analyses. Buildings XI, thermal performance of the exterior envelopes of whole buildings XI, CD-ROM proceedings, Clearwater Beach, Florida. Atlanta: ASHRAE; 2010.

[12] Kočí, J., Maděra, R. \& Černý, R., Generation of a critical weather year for hygrothermal simulations using partial weather data sets. Building and Environment, 76, pp. 54-61, 2014.

[13] Meteonorm 2010. Version 6.0, software version 6.1.0.20 from April 2010. Meteotest, Switzerland.

[14] Kočí, V, Kočí, J., Maděra, J. \& Černý, R., Computer code HEMOT for hygrothermal assessment of thermal insulation systems. Thermophysics 2010. Brno: Brno University of Technology, pp. 133-140, 2010.

[15] Kruis, J., Koudelka, T. \& Krejčí, T., Efficient computer implementation of coupled hydro-thermo-mechanical analysis. Mathematics and Computers in Simulations, 80(8), pp. 1578-1588, 2010.

[16] Jiřičková, M. \& Černý, R., Effect of hydrophilic admixtures on moisture and heat transport and storage parameters of mineral wool. Construction and Building Materials, 20(6), pp. 425-434, 2006.

[17] Jerman, M., Kočí, V., Maděra, J., Výborný, J. \& Černý, R., Water and heat transport parameters of materials involved in AAC-based building envelopes. 1st Central European symposium on building physics, Lodz: Technical University of Lodz; pp. 39-45, 2010.

[18] Vejmelková, E., Pavlíková, M., Keppert, M., Keršner, Z., Rovnaníková, P., Ondráček, M., Sedlmajer, M. \& Černý, R., High performance concrete with Czech metakaolin: experimental analysis of strength, toughness and durability characteristics. Construction and Building Materials, 24(8), pp. 1404-1411, 2010. 
[19] Jerman, M., Keppert, M., Výborný, J. \& Černý, R., Moisture and heat transport and storage characteristics of two commercial autoclaved aerated concretes. Cement Wapno Beton, 1, pp. 18-29, 2011.

[20] Jerman, M. \& Černý, R., Effect of moisture content on heat and moisture transport and storage properties of thermal insulation materials. Energy \& Buildings, 53, pp. 39-46, 2012.

[21] Kočí, J., Žumár, J., Pavlík, Z. \& Černý, R., Application of Genetic Algorithm for Determination of Water Vapor Diffusion Parameters of Building Materials. Journal of Building Physics, 35(3), pp. 238-250, 2012.

[22] Kočí, J., Maděra, J., Jerman, M. \& Černý, R., Determination of moisture diffusivity of AAC in drying phase using genetic algorithm. Proceedings of World Academy of Science, Engineering and Technology, 61, pp. 863-868, 2012.

[23] Kučerová, A., Identification of nonlinear mechanical model parameters based on soft computing methods, $\mathrm{PhD}$ thesis, Ecole Normale Supérieure de Cachan, 2007. 